\title{
AVALIAÇÃO DA CONDUTIVIDADE HIDRÁULICA PARA SOLOS COMPACTADOS UTILIZADOS EM CAMADAS SELANTES E ANÁLISE DE ESTABILIDADE DE ATERRO PARA RESÍDUOS SÓLIDOS DA PERFURAÇÃO DE POÇOS DE PETRÓLEO
}

\author{
A. C. Pereira ${ }^{1}$; F. Q. Porto Filho; O. Freitas Neto e R. N. F. Severo \\ Instituto Federal de Educação, Ciência e Tecnologia do Rio Grande do Norte \\ E-mail: alexandre.pereira@ifrn.edu.br ${ }^{1}$
}

Submetido em agosto de 2013 e aceito em agosto de 2013

\section{RESUMO}

Este estudo avaliou geotecnicamente (ensaios de laboratório, de campo e simulações numéricas) realizados com o objetivo de caracterizar solos naturais e solos compactados para projeto e execução de células de aterro para resíduos industriais oriundos da atividade petrolífera que, pelo fato de não se enquadrarem nas classificações de resíduos Classe I (Perigosos) ou Classe II-B (Não Perigosos/Inertes), podendo ter propriedades como biodegradabilidade, combustibilidade ou solubilidade em água, são classificados como não perigosos (Classe II-a: Não inertes - NBR10.004/2004). Para a necessária avaliação da segurança da obra frente ao risco de contaminação pela percolação pela base dos aterros, bem como referente à avaliação da segurança frente ao risco de ruptura dos taludes de contenção, o presente trabalho tratará da avaliação dos seguintes pontos: avaliação da capacidade do solo compactado (camada selante) da base do aterro em propiciar valores de condutividade hidráulica inferiores a $10-7 \mathrm{~cm} / \mathrm{s}$ (proteção eficiente e segura do lençol freático) e avaliação da estabilidade dos taludes projetados. Conclui-se que os estudos de campo realizados para a determinação da condutividade hidráulica dos solos indicam que os materiais avaliados podem ser caracterizados como de baixa condutividade hidráulica. As análises da estabilidade por métodos de equilíbriolimite, com o auxilio da ferramenta computacional, mostraram que o talude apresenta-se estável e não sujeito a grandes deslizamentos, pois os fatores de segurança calculados por diferentes métodos resultaram valores bem maiores que o mínimo (FSmin $=1,5$ ) para qualquer um dos métodos utilizados, mesmo com a redução dos parâmetros de resistência dos solos em $40 \%$.

PALAVRAS-CHAVE: Risco Geotécnico, Análise de Estabilidade, Aterros de Resíduos, Contaminação do Solo, Condutividade Hidráulica.

\section{EVALUATION OF HYDRAULIC CONDUCTIVITY ON COMPACTED SOIL APPLIED TO LINER AND SLOPE STABILITY ANALYSIS TO WASTE LANDFILL FOR SOLID OIL DRILL RESIDUES}

\begin{abstract}
This study aimed to evaluate by means of laboratory tests, field tests and numerical simulations, of characterizing the natural and compacted soils used in landfill design and construction industry in the oil sector. For the construction of the landfill was necessary implementation of an experimental program to characterize the subsurface of the landfill site area from SPT and Geophysical testing, characterization of the three soils (Soil "1" Soil "2" Soil "3") used in the construction of the landfill, the evaluation of potential soil contamination by means of infiltration tests, evaluation of slope stability. The three soils analyzed were classified according to USCS as $\mathrm{MH}, \mathrm{GM}$ and SC respectively. From the trials in the field of infiltration by
\end{abstract}

the method of concentric cylinders was determined hydraulic conductivity of compacted soil that was approximately $10-7 \mathrm{~m} / \mathrm{s}$. The strength parameters of soils were obtained by empirical correlations that related to cohesion and friction angle of soil with plasticity index of soils. As recommended by the NBR $11682 / 2009$, we applied a factor of cohesion and the mitigation was thereafter performed slope stability analysis by method of Fellenius, Bishop and Janbu. The slope stability analysis by limit equilibrium methods, show the equilibrium analysis of slopes with safety factors calculated for various methods induces to the upper range minimum (FSmin = 1.5) for each method.

KEYWORDS: Hydraulic Conductivity, Slope Stability Analysis, Drill Residues. 


\section{AVALIAÇÃO DA CONDUTIVIDADE HIDRÁULICA PARA SOLOS COMPACTADOS UTILIZADOS EM CAMADAS SELANTES E ANÁLISE DE ESTABILIDADE DE ATERRO PARA RESÍDUOS SÓLIDOS DA PERFURAÇÃO DE POÇOS DE PETRÓLEO}

\section{OBJETIVOS DO TRABALHO}

Para a necessária avaliação da segurança da obra frente ao risco de contaminação pela percolação pela base dos aterros, bem como referente à avaliação da segurança frente ao risco de ruptura dos taludes de contenção, o presente trabalho tratará da avaliação dos seguintes pontos: avaliação da capacidade do solo compactado (camada selante) da base do aterro em propiciar valores de condutividade hidráulica inferiores a $10^{-7} \mathrm{~cm} / \mathrm{s}$ (proteção eficiente e segura do lençol freático) e avaliação da estabilidade dos taludes projetados.

Este estudo avaliou geotecnicamente (ensaios de laboratório, de campo e simulações numéricas) realizados com o objetivo de caracterizar solos naturais e solos compactados para projeto e execução de células de aterro para resíduos industriais oriundos da atividade petrolífera que, pelo fato de não se enquadrarem nas classificações de resíduos Classe I (Perigosos) ou Classe II-B (Não Perigosos/Inertes), podendo ter propriedades como biodegradabilidade, combustibilidade ou solubilidade em água, são classificados como não perigosos (Classe II-a: Não inertes - NBR10.004/2004). Conforme prevê o projeto do aterro, de propriedade de empresa que presta serviços à Petrobras, a obra está concebida para desenvolver-se em etapas sucessivas, devendo alcançar a altura máxima de 19,15m ao final de sua vida útil (capacidade para volume total de resíduos de $604.000 \mathrm{~m}^{3}$ ).

Foram os seguintes os estudos e ensaios realizados: análise de relatórios de ensaios de laboratório: Análise granulométrica, limites de liquidez e de plasticidade, compactação (ensaio Proctor: energia intermediária e modificado) e permeabilidade, avaliação dos perfis de sondagem tipo SPT (Standard Penetration Test) e geofísicos (eletrorresistividade) realizados, ensaios de campo: Infiltração mediante método cilindros concêntricos bem como a análise de estabilidade dos taludes do aterro conforme procedimentos preconizados na NBR 11.682 (2004).

\section{MATERIAIS E MÉTODOS}

O presente trabalho visa apresentar a metodologia empregada para estudos geotécnicos (ensaios de laboratório, de campo e simulações numéricas) realizados com o objetivo de caracterizar solos naturais e solos compactados para projeto e execução de células de aterro para resíduos industriais oriundos da atividade petrolífera que, pelo fato de não enquadraremse nas classificações de resíduos Classe I (Perigosos) ou Classe II-B (Não Perigosos/Inertes), podendo ter propriedades como biodegradabilidade, combustibilidade ou solubilidade em água, são classificados como não perigosos (Classe II-a: Não inertes - NBR10.004/2004).

Conforme prevê o projeto do aterro, de propriedade de empresa que presta serviços à Petrobras, a obra está concebida para desenvolver-se em etapas sucessivas, devendo alcançar a altura máxima de 19,15m ao final de sua vida útil (capacidade para volume total de resíduos de $\left.604.000 \mathrm{~m}^{3}\right)$. 
Cada etapa compreenderá a execução de aterros laterais (diques) confinantes e de camada de solo selante (sobrejacente a geomembrana com espessura de $1,5 \mathrm{~mm}$ ) para funcionar. A impermeabilização do fundo do mesmo está concebida para ser executada com material argiloso, com condutividade hidráulica de no mínimo $10^{-7} \mathrm{~cm} / \mathrm{s}$, visando garantir a condição de selante em cinco áreas sucessivas de aproximadamente $10.000 \mathrm{~m}^{2}$, confinadas lateralmente por obras de aterro com seção trapezoidal, com altura variando de 4,15m (1a camada, no trecho com cotas mais baixas) a 3,0m, e dimensões de $15 \mathrm{~m}$ para a base maior e $4,5 \mathrm{~m}$ para a menor (coroamento), possuindo taludes com inclinações ( $\mathrm{V}: \mathrm{H}$ ) de 1:1,5 à montante (contato com o material de resíduo) e 1:2 à jusante (talude externo).

As Figuras 01 a 03 apresentam detalhes sobre a geometria da seção transversal do talude do aterro em questão, dimensões dos aterros confinantes (diques) e do sistema de drenagem e proteção dos taludes da obra.

Considera-se que o aterro de resíduos sólidos em questão apresenta como condicionantes fundamentais os aspectos relacionados ao risco de contaminação do meioambiente, seja devido à possibilidade de percolação de contaminantes nos solos sobrejacentes e circundantes ao aterro, seja pelo risco de ruptura dos taludes laterais que os confinam lateralmente.

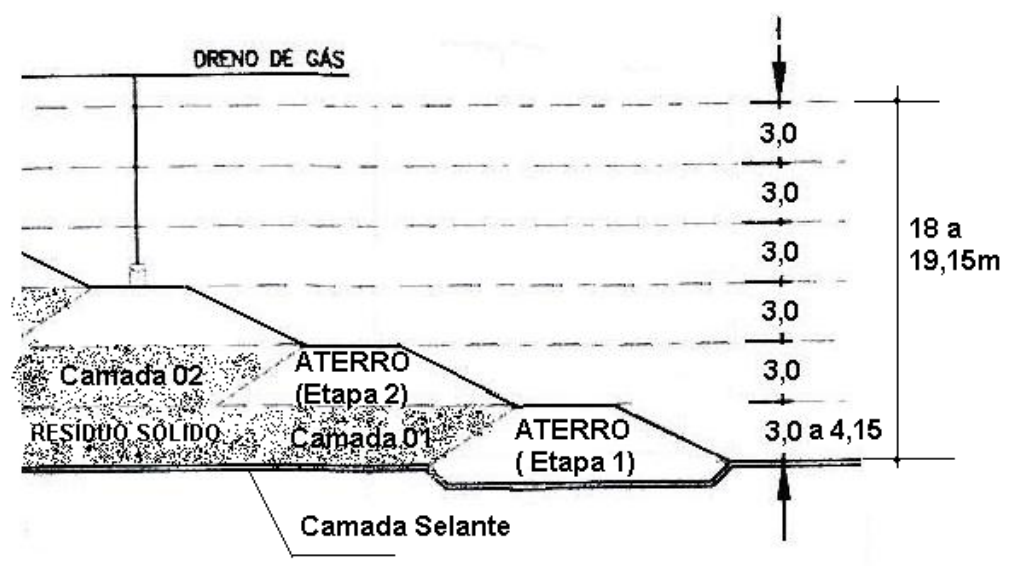

Figura 01- Detalhe de seção transversal do aterro (Pereira e Porto Filho, 2007).

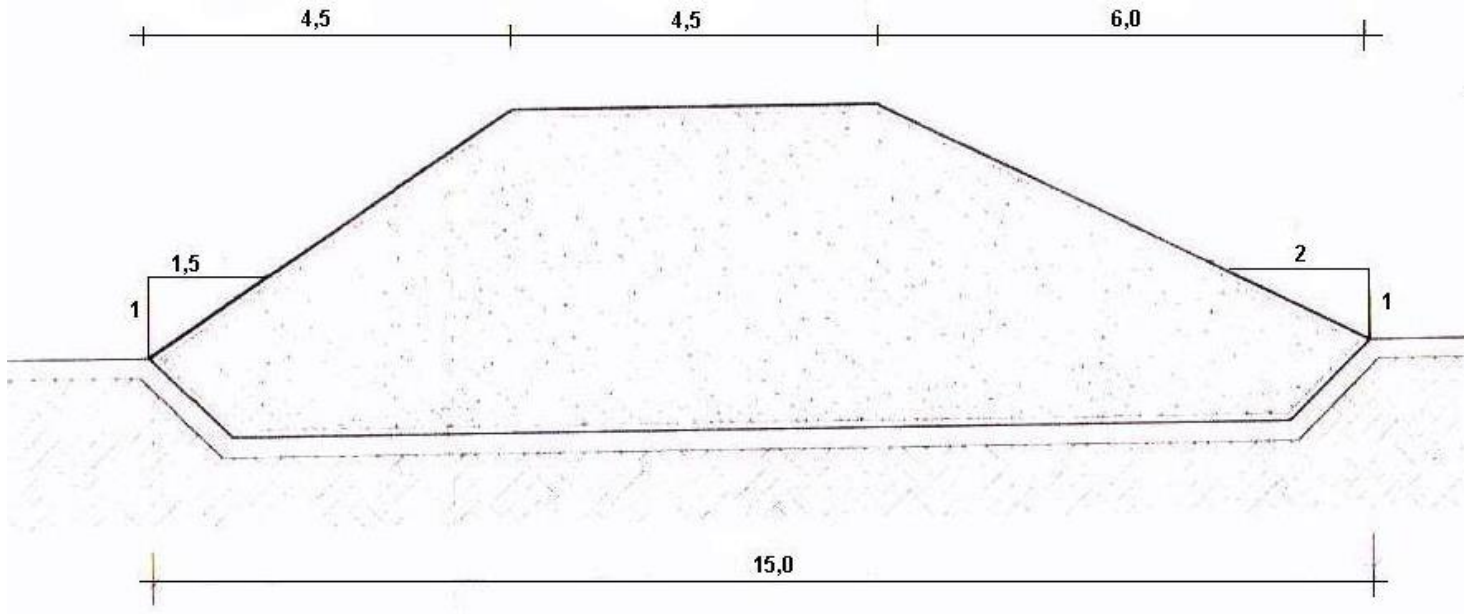

Figura 02- Dimensões dos aterros confinantes (seção tipo dos diques) (Pereira e Porto Filho, 2007). 


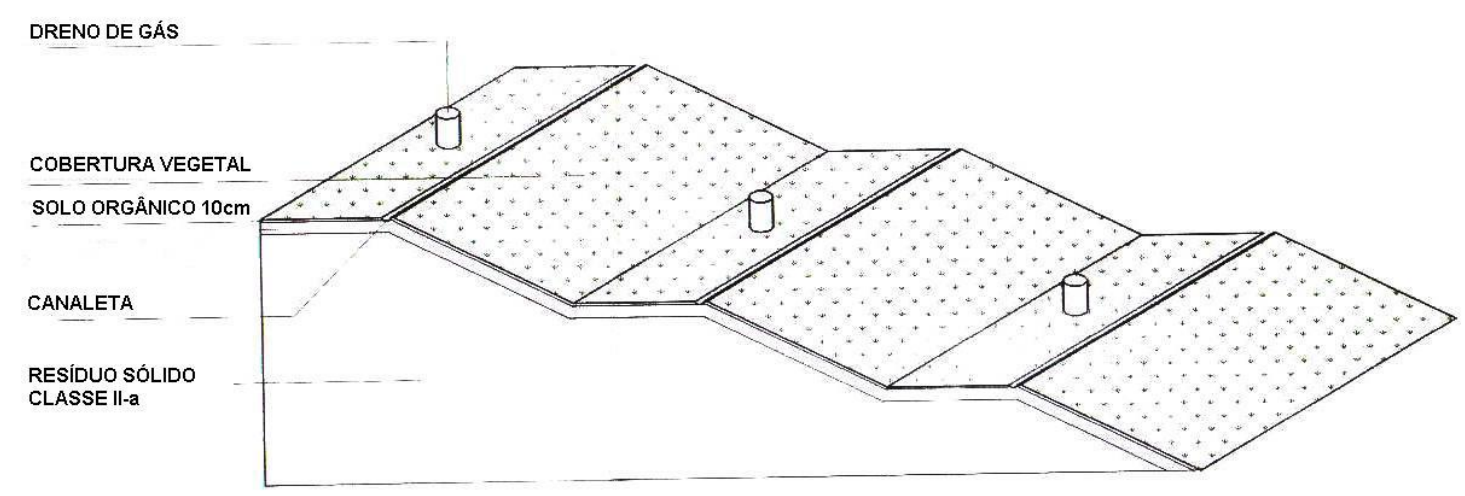

Figura 03- Detalhes do sistema de drenagem e proteção dos taludes da obra (Pereira e Porto Filho, 2007).

Segundo a NBR10157/87, que trata da questão das condições mínimas exigíveis para projeto e operação de aterros de resíduos industriais perigosos, de forma a proteger adequadamente os mananciais hídricos superficiais e subterrâneos próximas, bem como os operadores destas instalações e populações vizinhas, estudos geotécnicos são necessários quanto à avaliação da estabilidade dos taludes de escavação e de aterro (para as fases de construção e de operação) e ao pré-dimensionamento dos sistemas de impermeabilização (fundo, taludes e cobertura final) utilizando solos compactados e geossintéticos.

Convém que se destaque a importância dos estudos geológico-geotécnicos visando tanto à adequada escolha do local para a implantação das obras, em função dos condicionantes geoambientais e das características dos materiais de fundação e de construção dos aterros, como a correta definição do projeto e execução da obra.

Quanto às características de interesse para a necessária avaliação da segurança da obra frente ao risco de contaminação pela percolação pela base dos aterros, bem como referente à avaliação da segurança frente ao risco de ruptura dos taludes de contenção, o presente trabalho tratará da avaliação dos seguintes pontos:

- Avaliação da capacidade do solo compactado (camada selante) da base do em propiciar valores de condutividade hidráulica inferiores a $10^{-7} \mathrm{~cm} / \mathrm{s}$ (proteção eficiente e segura do lençol freático).

- Avaliação da estabilidade dos taludes projetados.

Foram os seguintes os estudos e ensaios realizados:

i. Análise de relatórios de ensaios de laboratório: Análise granulométrica, limites de liquidez e de plasticidade, compactação (ensaio Proctor: energia intermediária e modificada) e permeabilidade.

ii. Avaliação dos perfis de sondagem tipo SPT (Standard Penetration Test) e geofísicos (eletrorresistividade) realizados.

iii. Ensaios de campo: Infiltração mediante método cilindros concêntricos. 
iv. Análise de estabilidade dos taludes do aterro conforme procedimentos preconizados na NBR 11.682 (2004).

\section{PROCEDIMENTO EXPERIMENTAL}

\subsection{Perfil Geotécnico (SPT)}

Foram realizados 15 (quinze) furos de sondagem de simples reconhecimento de solos (SPT: Standard Penetration Test), perfazendo um total de 36 (trinta e seis) metros. A sondagem foi realizada conforme a Norma NBR6484 da Associação Brasileira de Normas Técnicas.

\subsection{Ensaios Geofísicos}

Foram realizados estudos geofísicos mediante o método de perfilagem elétrica para a avaliação das condições hidrogeológicas da área de propriedade da ESBra S.A., situada na localidade de Sítio Novo (aproximadamente a $2 \mathrm{~km}$ à direita do km50 da BR304) localizada à sudeste do município de Mossoró-RN.

O método geofísico empregado para a definição dos perfis elétricos (eletrorresistividade) consiste em um dos mais utilizados na prospecção de água subterrânea, seja para fins de projeto e execução de poços como para a avaliação da presença e condições de circulação de água para fins diversos.

No caso do estudo em questão, a prospecção geofísica foi realizada no objetivo da obtenção de informações a respeito da existência de estruturas geológicas potencialmente suscetíveis de apresentar características e propriedades hidrogeológicas com importância para o estudo do regime e sentido de fluxo de águas subterrâneas na fundação da obra do aterro para disposição de resíduos industriais Classe II-a, propiciando, assim, o adequado conhecimento acerca do eventual percurso de percolados que por ventura venham a atravessar a geomembrana e a camada de solo compactado disposta na base das células do aterro.

Convém destacar que métodos potenciais como o da prospecção geofísica da eletrorresistividade das formações geológicas apresentam elevado grau de confiabilidade, sendo, inclusive, capazes de propiciar a prospecção mediante certo controle da profundidade a ser objeto de investigação, associado a baixos custos relativos.

Para a execução dos ensaios geofísicos foi utilizada o arranjo proposto por Schlumberger, com abertura $A B$ (alinhamento entre os extremos direito e esquerdo do resistivímetro) máxima de $1.600 \mathrm{~m}$, com os eletrodos dispostos mantendo a relação $\mathrm{NM} \mathrm{AB/5}$.

Os estudos sobre a geologia regional e as observações de campo conduziram à caracterização da área como constituída geologicamente por calcários do topo da Formação Jandaíra, geralmente margosos e com circulação cárstica apresentada pelos aqüíferos.

O ambiente de estudo é caracterizado geomorfologicamente pela predominância tabular, com topografia bastante plana e espessuras da ordem de 150 a $200 \mathrm{~m}$, sobrepostos em contatos gradativos a calcarenitos (geralmente sem aqüíferos importantes), com espessuras da 
ordem de $150 \mathrm{~m}$. Sotoposto a este pacote sedimentar de calcários/calcarenitos há a ocorrência da Formação Açu (arenitos), também de idade cretácea, com espessuras consideráveis.

Registra-se a característica ocorrência de intercalações de lentes de folhelhos bem como a presença de estratos com granulometria mais grosseira (conglomerados) e com bons aqüíferos encaixados na seção basal (profundidades de até 1.000 a $1.500 \mathrm{~m}$ ).

\subsection{Campanha de Ensaios Geotécnicos de Laboratório}

\subsubsection{Amostragem de Solos}

As Figuras 4 e 5 mostram a aparência dos solos "1", "2" e " 3 " que foram objeto de estudo para fins de utilização como material de construção para a execução da camada selante e aterros laterais (diques).

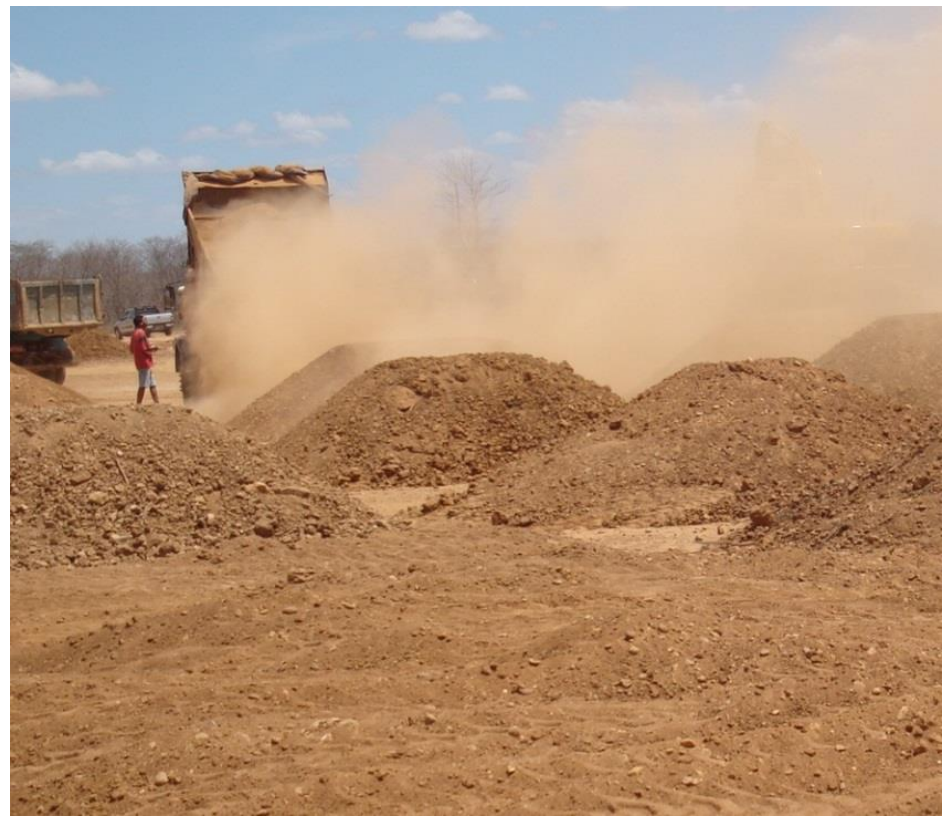

Figura 4- Solo a ser empregado para a execução da camada selante (Solo 1).

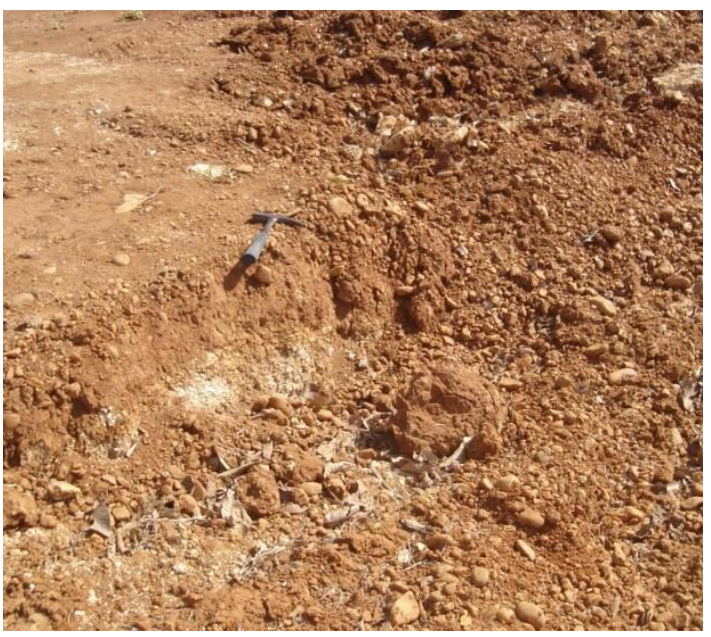

(a)

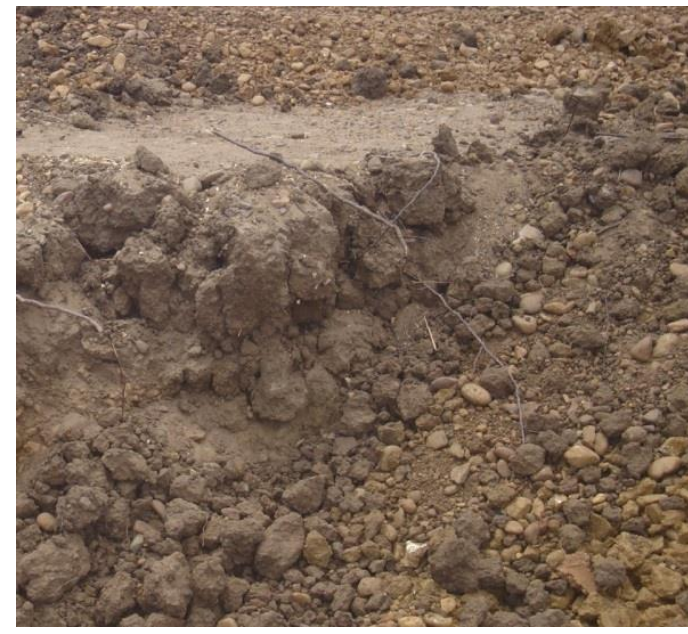

(b)

Figura 5- Solos "2" (a) e “3" (b) estudados para emprego como material para os diques. 


\subsubsection{Análise Granulométrica}

Para a análise granulométrica dos solos estudados se procedeu à avaliação de ensaios de peneiramento para a determinação das curvas granulométricas representativas para solos de jazida, solos compactados e solos subjacentes ao solo de base das células dos aterros. Os solos foram obtidos em jazida ao lado direito da BR304, a 2,5km da localidade de Sítio Novo (Zona rural de Mossoró-RN), em profundidades de 0 a $70 \mathrm{~cm}$.

Para os três solos estudados, foram os seguintes os valores encontrados para a porcentagem passando nas peneiras \#2", \#1", \#3/8", $N^{\circ} 4, N^{\circ} 10$ e $N^{\circ} 200$ :

Quadro 01- Quadro resumo com os resultados da granulometria (Pereira e Porto Filho, 2007).

\begin{tabular}{|c|c|c|c|c|c|c|c|}
\hline \multirow{2}{*}{ SOLO } & \multicolumn{9}{|c|}{ \% PASSANDO } \\
\cline { 2 - 8 } & $\# 2 "$ & $\# 1 "$ & $\# 3 / 8 "$ & $N^{\circ} 4$ & $N^{\circ} 10$ & $N^{\circ} 40$ & $N^{\circ} 200$ \\
\hline "Solo 1" & 100 & 100 & 100 & 99 & 97 & 85 & 68 \\
\hline "Solo 2" & 100 & 91 & 69 & 63 & 57 & 53 & 38 \\
\hline "Solo 3" & 100 & 100 & 97 & 96 & 92 & 71 & 35 \\
\hline
\end{tabular}

\subsubsection{Limites de Atterberg}

Para a determinação de índices de consistência dos solos estudados se procedeu à realização de ensaios para encontrar valores representativos para os limites de liquidez (ABNT NBR 6459/84) e de plasticidade (ABNT NBR 7180/84) de solos para emprego como material de construção para a execução da camada selante e aterros laterais (diques). Com base na classificação proposta por Casagrande, quanto à sua fração fina os solos estudados como de comportamento siltoso de alta compressibilidade (Solos 1 e 2) ou argiloso com baixa plasticidade (Solo 3).

Foram os seguintes os valores encontrados para as umidades correspondentes aos limites de liquidez (LL) e de plasticidade (LP), bem como para os índices de plasticidade para os solos (IP = LL $-\mathrm{LP})$ :

Quadro 02- Quadro resumo com os resultados de limites de Atterberg (Pereira e Porto Filho, 2007).

\begin{tabular}{|c|c|c|c|}
\hline SOLO & LL (\%) & LP (\%) & IP (\%) \\
\hline "Solo 1" & 53 & 35 & 18 \\
\hline "Solo 2" & 51 & 35 & 16 \\
\hline "Solo 3" & 32 & 23 & 9 \\
\hline
\end{tabular}

\subsubsection{Parâmetros de Compactação e índice CBR}

Para a determinação da curva de compactação representativa dos solos estudados se procedeu à realização de ensaio de compactação segundo método Proctor, energias intermediária (Solos "2" e "3": Materiais para aterros laterais) e modificada ("Solo 1": Material para camada selante). Os ensaios foram realizados em conformidade com procedimentos normatizados pelos Métodos de Ensaio DNER-ME 162/94 e ABNT NBR 7182/84.

\subsubsection{Parâmetros de Resistência ao Cisalhamento}


Para a realização da análise de estabilidade dos taludes do aterro que constitui o maciço de solo que contorna o aterro para a disposição de resíduos industriais, faz-se necessária a consideração de adequados parâmetros para a avaliação da resistência a cisalhamento apresentada pelo material. Para o estudo da resistência ao cisalhamento dos solos empregados para obra em questão, por ser concebida para ser constituída por materiais compactados, faz-se necessário que se conheça a influência da umidade de compactação do solo e do processo empregado para a compactação, dos quais resultam o peso específico seco, o grau de saturação e a estrutura do solo.

O ângulo de atrito interno e o intercepto de coesão correspondem aos parâmetros fundamentais que caracterizam os solos frente à resistência à compactação, para uma dada tensão normal efetiva atuante $\sigma^{\prime}$ e um correspondente valor para tensão cisalhante efetiva $\tau^{\prime}$, a envoltória de resistência consistirá no limite para tensões cisalhantes antes da ruptura. Mediante o conhecimento dos parâmetros C (intercepto de coesão) e $\phi$ (ângulo de atrito) efetivos, poder-se-á traçar a envoltória e proceder-se à avaliação do estado de tensões do material.

Os parâmetros de resistência podem ser definidos tanto deterministicamente, mediante a adequada seleção do método e condições de ensaio a empregar (cisalhamento direto, triaxial, ensaios in situ...), como por intermédio de correlações empíricas e métodos probabilísticos. Quanto à obtenção dos parâmetros de resistência ao cisalhamento por meio de ensaios de laboratório, possui especial importância a qualidade e representatividade do corpo de prova empregado. Correlações baseadas na experiência com solos compactados têm se mostrado suficientemente satisfatórias quando se buscam correlacionar o $\gamma_{d}$ máximo e com a umidade ótima, o índice de plasticidade (IP) com o valor correspondente ao intercepto de coesão (C), que também têm sido objeto de correlações com o ângulo de atrito interno $(\phi)$.

No presente estudo, para a definição dos valores para C e $\phi$ correspondentes aos solos "1", "2" e "3", bem como para o material a ser disposto como resíduo no aterro, recorreu-se a correlações estatísticas propostas na literatura (CRUZ, $1969^{1}$ apud CAVALCANTE e COUTINHO, $2006^{2}$ ) e banco de dados publicado por CRUZ (1995) ${ }^{3}$. As Equações 1 e 2 apresentadas abaixo consistem naquelas que foram empregadas para a definição dos parâmetros de resistência ao cisalhamento para os materiais estudados.

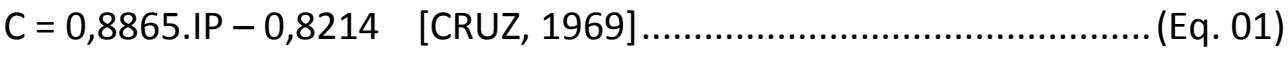

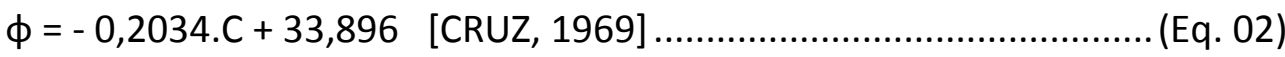

\subsection{Ensaios Geotécnicos In Situ}

\footnotetext{
1 Cruz, P.T. Propriedades de Engenharia de Solos Residuais Compactados da Região Sul do Brasil, THEMAG/DLP/EPUSP, São Paulo, 1969.

${ }^{2}$ Cavalcante, S.P.P e Coutinho, R.Q. Análise de Parâmetros Geotécnicos dos Solos Compactados de Barargens do Estado do Ceará, In: COBRAMEG'2006, pp. 2025-2030, 2006.

3 Cruz, P.T. 100 Barargens Brasileiras: Casos Históricos, Materiais de Construção e Projeto, Oficina de Textos/FAPESP, São Paulo, 1995.
} 
Foram realizados ensaios para determinação da condutividade hidráulica mediante de infiltração segundo o método de anéis concêntricos. Para determinação da velocidade de infiltração instantânea (I) da camada superficial da base do aterro utilizou-se o método dos anéis concêntricos com carga constante (Fig. 10), confeccionando-se equações do tipo potencial, conforme descrito por Klar (1991) ${ }^{4}$. A velocidade de infiltração básica $\left(I_{b}\right)$ foi considerada como o valor de "I" ao final dos testes. Para abastecimento do anel central utilizou-se proveta plástica de $500 \mathrm{ml}$.

O espaço entre os dois anéis foi mantido com água no mesmo nível do anel central. As leituras foram realizadas inicialmente a intervalos de 5, 10, 15 e 30 minutos e, depois, de hora em hora. Dos valores ocorridos durante o período de cada ensaio foi descontada a respectiva evaporação. Em cada bacia foram realizados três testes, em locais escolhidos aleatoriamente.
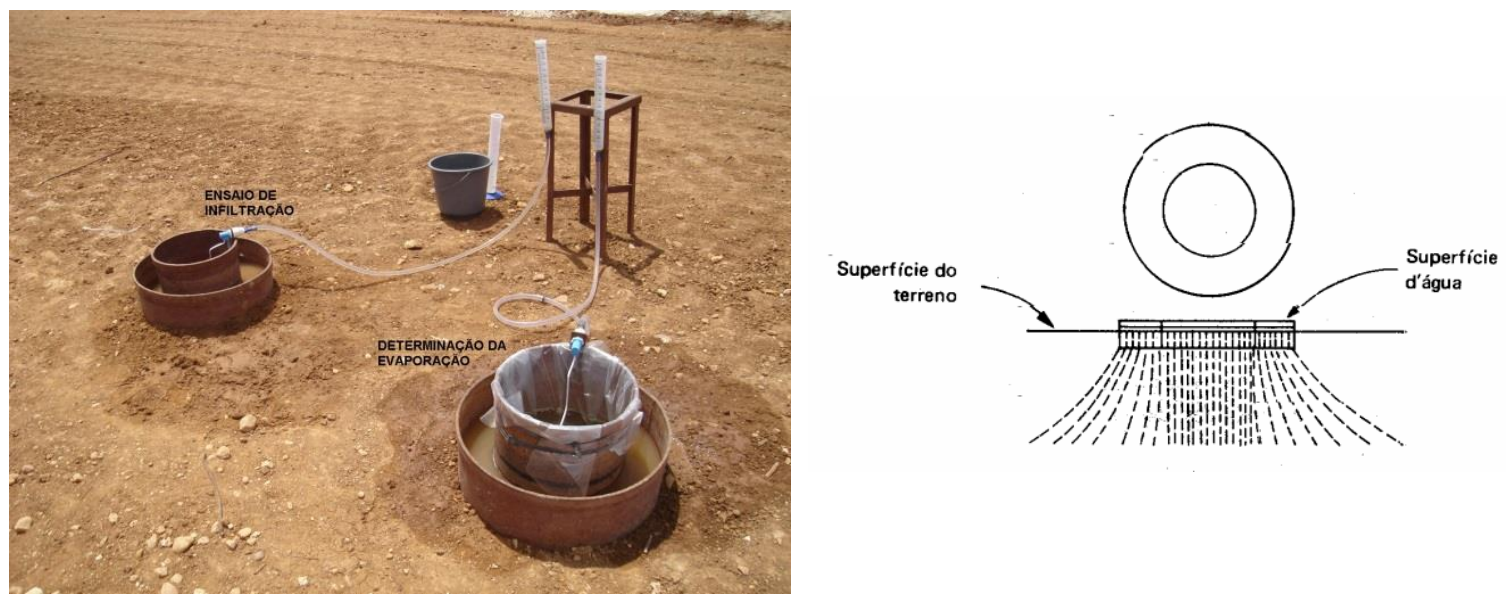

Figura 6- Esquema para a realização dos ensaios de infiltração.

\subsection{Método Considerado para Análise de Estabilidade de Taludes}

Para a análise de estabilidade dos taludes do aterro de resíduos industriais objeto de estudo, foram utilizados os métodos propostos por Fellenius, Bishop e Janbu, para as condições de ruptura global com superfície de ruptura imposta passando pelo resíduo, com e sem percolação para os casos de redução e não-redução em $40 \%$ nos valores dos parâmetros $C$ e $\phi$ considerados como representativos para utilização na análise de estabilidade dos taludes. A análise da estabilidade dos taludes frente ao deslizamento foi realizada para ambos os solos considerados (solos "2" e " 3 ").

Também avaliada a condição de ruptura tanto global como no corpo do aterro que constitui o talude, segundo os métodos propostos por Fellenius, Bishop e Janbu, para os estados com e sem percolação, nos casos de redução e de não-redução em $40 \%$ nos valores dos parâmetros $\mathrm{C}$ e $\phi$ considerados como representativos para utilização na análise de estabilidade dos taludes.

A análise da estabilidade dos taludes frente ao deslizamento foi realizada para ambos os solos considerados (solos " 2 " e "3") mediante a utilização do software Geoslope.

${ }^{4}$ Klar E. A., Irrigação: Freqüência e Quantidade de Aplicação, Nobel, p. 66-79, São Paulo, 1991. 


\section{ANÁLISE DOS RESULTADOS}

\subsection{Caracterização e Classificação Geotécnica dos Solos Estudados}

\subsubsection{Perfil Geotécnico (ensaio SPT)}

O Quadro 03 apresenta a correspondente classificação geotécnica dos materiais identificados no processo de amostragem durante a realização de ensaio de prospecção geotécnica in situ mediante o método SPT (Standard Penetration Test).

Convém destacar que em nenhum dos furos de sondagem realizados foi identificada presença de nível d'água, tendo sido procedida à perfuração a seco dos furos de sondagem, com profundidades variando entre 1,0 a 4,0m, atingindo nessas profundidades estratos com textura argilo-pedregulhosa valores para o $\mathrm{N}_{\mathrm{SPT}}$ em torno de 60 golpes $/ 30 \mathrm{~cm}$, valor característico de materiais com consistência dura. Na Figura 7 se apresenta gráfico com a variabilidade em relação aos valores obtidos para o índice de resistência à penetração $\left(\mathrm{N}_{\mathrm{SPT}}\right)$ nos furos de sondagem executados. Verifica-se que o perfil geotécnico do solo investigado caracteriza-se pela rápida ocorrência de estratos com valores para índices de resistência à penetração superior a 20 golpes $/ 30 \mathrm{~cm}$, sendo que em 10 dos perfis (2/3 do total) foram encontrados $N_{\text {SPT }} \geq 20$ ainda no primeiro metro de ensaio. Em apenas um dos furos de sondagem realizados (Furo SPT-13) foi constatada a ocorrência de material (argila branca) com $\mathrm{N}_{\mathrm{SPT}} \leq 10$ nos dois primeiros metros do ensaio.

Quadro 03- Classificação geotécnica dos materiais (Pereira e Porto Filho, 2007).

\begin{tabular}{|c|c|}
\hline Classificação do Material & $Z(m)$ \\
\hline Superfície & 0,0 \\
\hline Argila Branca/Amarela/Preta, média a rija, com pedregulho & $-1,0$ \\
\hline Argila Amarela/marrom, dura, com pedregulho & $-2,0$ \\
\hline Argila Amarela/marrom, dura, com pedregulho & $-3,0$ \\
\hline $\begin{array}{l}\text { Argila Amarela/marrom, dura, com pedregulho, contato } \\
\text { com topo da Formação Jandaíra (Calcários Margosos) }\end{array}$ & $-4,0$ \\
\hline
\end{tabular}




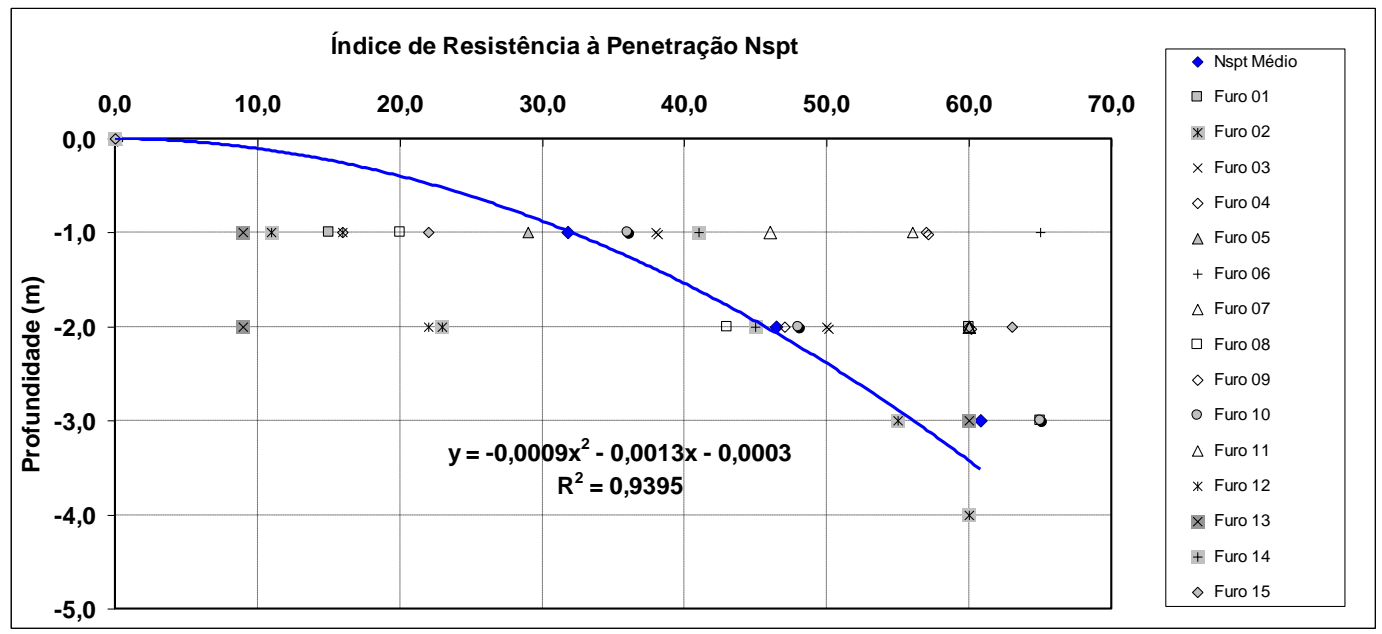

Figura 7- Perfil representativo para o índice de resistência à penetração $\left(N_{S P T}\right)$ nos furos de sondagem executados (Pereira e Porto Filho, 2007).

\subsubsection{Ensaios Geofísicos}

Em relação à análise da sondagem elétrica vertical, constata-se que a prospecção realizada para profundidades de investigação de 500 a 550m não identificou indícios de potencial hidrogeológico importante para o Arenito Açu, com níveis aqüíferos imperceptíveis sob o ponto de vista geoelétrico, tendo em vista a curva ter se mostrado sem inflexões e com angulação forte em relação ao eixo das abscissas. Quanto aos perfis elétricos, realizados em um total de 12 (doze), foi observado que não há indícios de continuidade no alinhamento das fraturas existentes em eventuais aqüíferos cársticos, principalmente em relação aos perfis realizados nas partes Leste e Sul da área estudada (região próxima à área de instalação do aterro para disposição de resíduos sólidos), que não acusaram fraturas em profundidade (Figura 8).

$\mathbf{N}$

Perfil Elétrico 03

S



Figura 8- Perfil elétrico sem indícios de acusar fraturas em profundidade.

Observa-se, portanto, que a área estudada apresenta baixíssimo potencial hidrogeológico, com resistividades aparentes variando entre 10 e $65 \Omega . m$, com as camadas superficiais (calcários pertencentes à Formação Jandaíra) apresentando os maiores valores para este parâmetro. Convém destacar que a direção dos perfis foi definida em função da disposição perpendicular em relação às supostas direções de fraturas. Entretanto, mesmo essa disposição para a malha de alinhamentos definida no processo de investigação não foi capaz de identificar na área estudada regiões com potencial hídrico importante. 
Em relação ao processo de circulação d'água subterrânea, considera-se que o comportamento cárstico dominante como a condição principal para a definição da circulação de água em seu interior e o correspondente estudo do regime e sentido de fluxo de águas subterrâneas e efluentes em seu interior.

Reforça-se a hipótese da inexistência de estruturas importantes que condicionem a existência de aqüíferos suspensos tanto a não identificação de nível d'água (lençol freático) em todos os 15 furos de sondagem realizados em setembro/2007 como a reduzida espessura de cobertura de solo e a natureza de carência na intercomunicação entre as fraturas identificadas nas formações superficiais (predominantemente calcários margosos) na área da prospecção geofísica.

Considera-se, portanto, em função dos resultados encontrados na prospecção geofísica, que a área estudada não apresenta formações e estruturas geológicas com potencialidade de propriedades hidrogeológicas características de áreas suscetíveis para acumulação de água, como indicam tanto os resultados da sondagem elétrica vertical como os perfis elétricos realizados.

\subsubsection{Ensaios Geotécnicos de Laboratório}

Fundamentando-se na análise dos resultados dos ensaios para caracterização granulométrica e para a obtenção dos limites de Atterberg, odemos classificar os solos em questão como de granulação grossa, matriz arenosa com finos, silto-argilosa.

Convém que se destaque a importante variabilidade em relação à presença de partículas na fração pedregulho ( $\phi \geq 4,8 \mathrm{~mm}$ ), de aproximadamente $37 \%$ de presença no solo "2" (GM) analisado. Em relação aos finos presentes nos solos, pode-se caracterizá-los como de plasticidade baixa ("Solo 3"; SC) e de alta compressibilidade ("Solo 1"; MH e "Solo 2"; GM).

Considerando-se a metodologia de classificação geotécnica dos solos proposta segundo o Sistema Unificado de Classificação dos Solos (SUCS), as amostras referentes de solos para emprego como material de construção para a execução da camada selante e aterros laterais (diques) receberiam as seguintes classificações:

Quadro 04- Quadro resumo com os resultados de limites de Atterberg (Pereira e Porto Filho, 2007).

\begin{tabular}{|c|c|}
\hline SOLO & CLASSIFICAÇÃO (SUCS) \\
\hline "Solo 1" & Silte com Alta Compressibilidade (MH) \\
\hline "Solo 2" & Pedregulho Siltoso de Alta Compressibilidade (GM) \\
\hline "Solo 3" & Areia Argilosa com Baixa Plasticidade (SC) \\
\hline
\end{tabular}

Em relação à análise dos parâmetros obtidos em ensaios de compactação e de CBR, a Figura 9 apresenta a posição relativa dos resultados para $\gamma_{d}$ máximo e umidade ótima para os três solos estudados, comparadas às curvas típicas para solos compactados. Os resultados dos ensaios realizados conduziram a curva de compactação, com valores correspondentes à massa específica aparente seca máxima e umidade ótima apresentados no quadro a seguir: 
Quadro 05- Quadro resumo com resultados de $\gamma_{d}$ máxima e umidade ótima e CBR (Pereira e Porto Filho, 2007).

\begin{tabular}{|c|c|c|c|c|}
\hline SOLO & $?_{\mathrm{d}}\left(\mathrm{kN} / \mathrm{m}^{3}\right)$ & $\mathrm{h}_{\mathrm{ot.}}(\%)$ & CBR (\%) & Expansão (\%) \\
\hline "Solo 1" & 17,55 & 16,7 & 10 & 0,2 \\
\hline "Solo 2" & 19,03 & 13,5 & 10 & 0,7 \\
\hline "Solo 3" & 18,60 & 14,4 & 7 & 0,3 \\
\hline
\end{tabular}

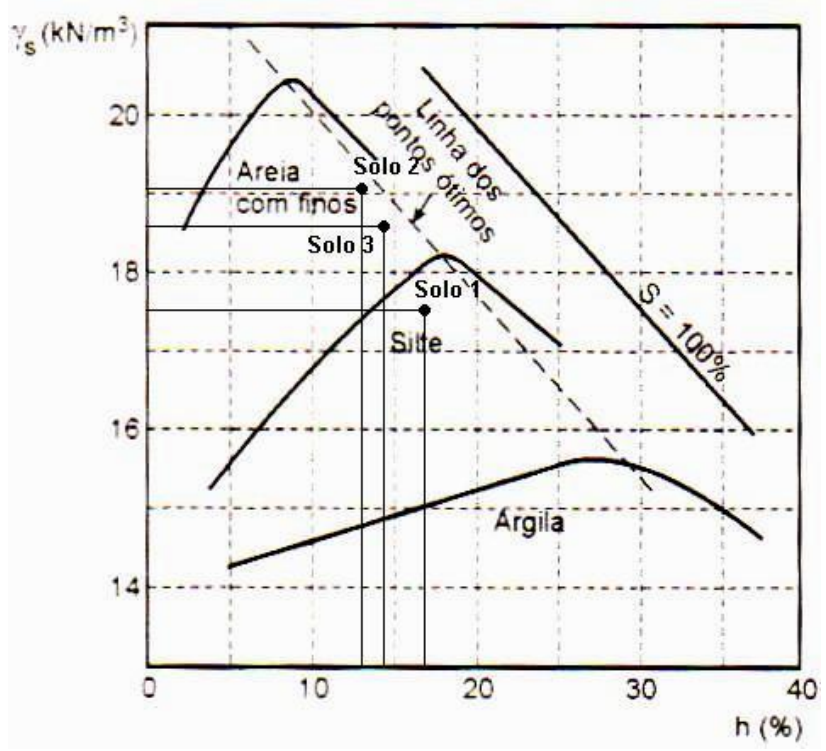

Figura 9- Solos estudados comparados a curvas de compactação típicas (Pereira e Porto Filho, 2007).

Pode-se observar que é reforçada a classificação dos solos em questão como de granulação grossa, matriz arenosa com finos, silto-argilosa, principalmente para o solo "2" (GM) analisado $\left(p_{\phi \geq 4,8 \mathrm{~mm}}=37 \%\right)$, todos apresentando valores de $\gamma_{\mathrm{d}}$ máximo superiores a $17 \mathrm{kN} / \mathrm{m}^{3}$ e valores para umidade ótima também característicos destes solos $\left(\mathrm{h}_{\mathrm{ot} .} \leq 17 \%\right)$.

Convém destacar-se a importância em se utilizar maior energia de compactação, propiciando maiores valores de massa específica aparente seca máxima e menores valores para o teor correspondente à umidade ótima. Embora as especificações não fixem intervalos de 疎 máxima e umidade ótima a serem obtidos, uma adequada adoção de desvio de umidade em relação à ótima e um grau mínimo de compactação de forma a ajustar o bom aproveitamento das operações de compactação. Para obras de terra de maior responsabilidade, que é o caso do aterro para disposição de resíduos sólidos em estudo, deve-se ter especial atenção ao controle dos procedimentos de compactação tanto em relação à execução dos aterros laterais (diques), como em relação à execução da camada de material selante a ser utilizada na base dos aterros.

Por exemplo, o emprego de teores de umidade $2,5 \%$ superiores à ótima e densidades em torno de $95 \%$ conduz a coeficientes de permeabilidade cerca de 10 vezes maior do que na umidade ótima e densidade máxima. A Figura 9 apresentada reforça a questão da importância que se deve atribuir ao adequado controle das operações de compactação, tanto em relação aos valores da condutividade hidráulica como em relação à específica aparente seca máxima alcançada na compactação. 


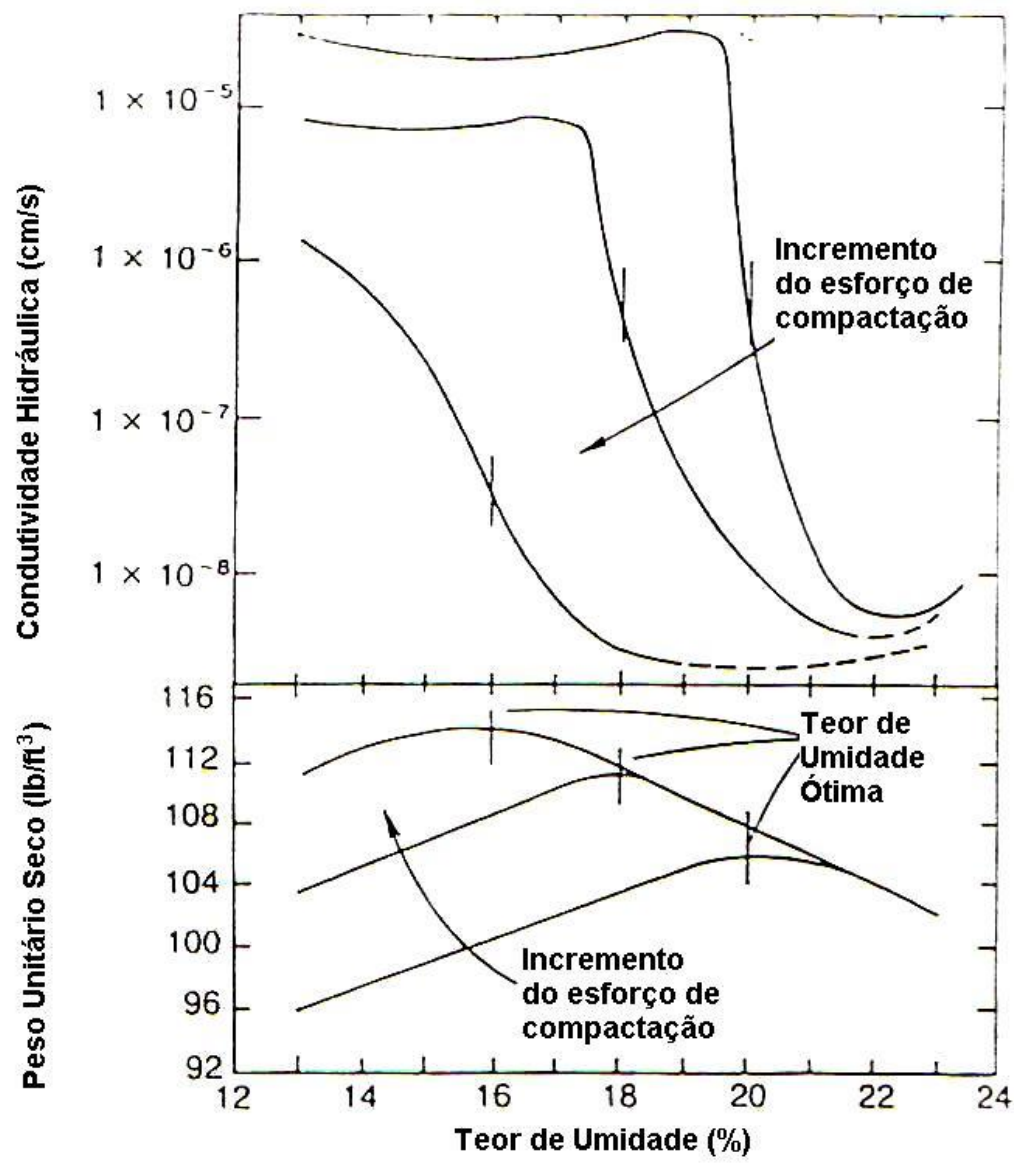

Figura 9- Influência da energia de compactação e do teor de umidade.

Observa-se que, para a mesma umidade, a permeabilidade do solo é tanto menor quanto mais compacto for o material, o que é simplesmente devido ao seu menor índice de vazios. Para a mesma densidade, a permeabilidade do material diminui com o aumento do teor de umidade, apesar do índice de vazios permanecer constante e os dois corpos de prove ficarem com o mesmo grau de saturação pelo efeito da própria água de percolação que aumenta a umidade do corpo de prova moldado mais seco.

Convém destacar, ainda, que existe importante diferenciação entre a estrutura dos solos compactados no ramo seco em relação ao ramo úmido, pois quando se compacta o solo sob condições de umidade correspondente ao ramo seco, a estrutura floculada imposta ao material proporciona uma maior facilidade para a percolação da água do que a estrutura dispersa característica do ramo úmido.

Em relação à obtenção de parâmetros para a resistência ao cisalhamento, em conformidade com correlações estatísticas propostas na literatura (CRUZ, 19695 apud

5 Cruz, P.T. Propriedades de Engenharia de Solos Residuais Compactados da Região Sul do Brasil, THEMAG/DLP/EPUSP, São Paulo, 1969. 
CAVALCANTE e COUTINHO, 2006 ) (Equações 01 e 02), propostas para o caso de rochas alcalinas, arenitos e solos coluvais, com $R^{2}$ de 0,4241 para Eq. 01 e $R^{2}$ de 0,4705 para Eq. 2, para os solos estudados, teríamos os parâmetros apresentados no Quadro 06 como representativos para C e $\phi$ correspondentes aos solos "1", "2" e "3" em questão.

Quadro 6- Parâmetros representativos para C e $\phi$ para os solos “1”, “2” e “3” (Pereira e Porto Filho, 2007).

\begin{tabular}{|c|c|c|c|c|c|}
\hline Solo & $\mathrm{IP}(\%)$ & $\gamma_{\mathrm{d}}\left(\mathrm{kN} / \mathrm{m}^{3}\right)$ & $\mathrm{C}(\mathrm{kPa})$ & $\Phi\left(^{\circ}\right)$ & Classificação SUCS \\
\hline "Solo 1" & 18 & 17,55 & 15,1 & 30,8 & $\mathrm{MH}$ \\
\hline "Solo 2" & 16 & 19,03 & 13,4 & 31,2 & $\mathrm{GM}$ \\
\hline "Solo 3" & 9 & 18,60 & 7,2 & 32,4 & $\mathrm{SC}$ \\
\hline
\end{tabular}

Quanto aos parâmetros de resistência a serem definidos como representativos para o material a ser disposto como resíduo sólido, considerando um valor de peso específico seco de $15 \mathrm{kN} / \mathrm{m}^{3}$ (valor informado pela empresa ESBra S.A.) para o material e a sua natureza de material previamente submetido a processo de incineração à temperatura aproximada de $800^{\circ} \mathrm{C}$, bem como a textura argilosa silto-arenosa para o material, foram admitidos os valores de $21 \mathrm{kPa}$ para o intercepto coesivo e $27,5^{\circ}$ para o ângulo de atrito interno na definição dos parâmetros de resistência ao cisalhamento do material.

\subsection{Ensaios de Infiltração}

Os testes foram realizados em trecho da célula 1 (primeira etapa da obra), em uma faixa da camada de solo utilizada como material de selo do aterro, com 20m de largura e comprimento correspondente à extensão total da base do aterro. Na região da obra escolhida para a realização dos ensaios foi realizado o controle dos parâmetros $\gamma_{\max }$ e umidade ótima de compactação obtidos para a energia modificada. A condutividade hidráulica da camada superficial foi determinada através da $\mathrm{I}_{\mathrm{b}}$ utilizando metodologia e equação apresentada por Millar $(1978)^{7}$. Os valores da condutividade hidráulica foram corrigidos para uma temperatura de $20^{\circ} \mathrm{C}$, mediante o emprego da equação abaixo:

$$
\mathrm{K}_{20}{ }^{\circ} \mathrm{C}=\mathrm{K}_{\mathrm{T}} \times \eta_{\mathrm{T}} / \eta_{20}{ }^{\circ} \mathrm{C}=\mathrm{K}_{\mathrm{T}} \times \mathrm{C}_{\mathrm{V}}
$$

Com:

$\mathrm{K}_{20}{ }^{\circ} \mathrm{C}$ Condutividade hidráulica a $20^{\circ} \mathrm{C}$.

$\mathrm{K}_{\mathrm{T}} \quad$ Condutividade hidráulica à temperatura ambiente.

$\eta_{20}^{\circ} \mathrm{C}$ Valor correspondente à viscosidade cinemática do fluido à temperatura de $20^{\circ} \mathrm{C}$.

$\eta_{T} \quad$ Valor correspondente à viscosidade cinemática do fluido à temperatura ambiente.

\footnotetext{
${ }^{6}$ Cavalcante, S.P.P e Coutinho, R.Q. Análise de Parâmetros Geotécnicos dos Solos Compactados de Barargens do Estado do Ceará, In: COBRAMEG'2006, pp. 2025-2030, 2006.

${ }^{7}$ MIllar, A. A., Drenagem de Terras Agrícolas: Bases Agronômicas, MacGraw Hill, p.126-127, 1978.
} 
As Figuras 10 a 15 abaixo, apresentam os resultados obtidos nos ensaios realizados de infiltração segundo o método de anéis concêntricos (Pereira e Porto Filho, 2007) ${ }^{8}$ :

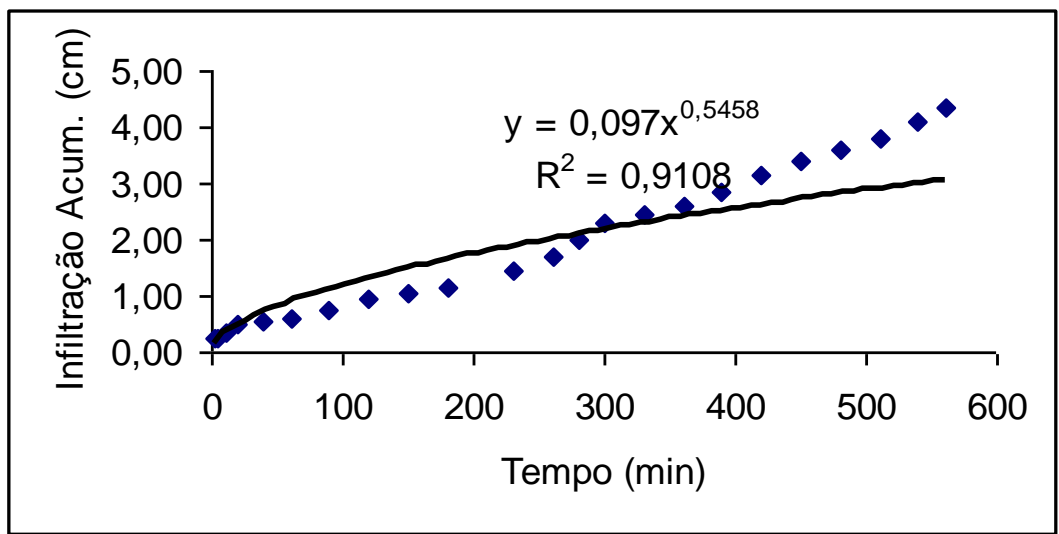

Figura 10- Gráfico de infiltração acumulada ao longo do período de ensaio no teste 1.

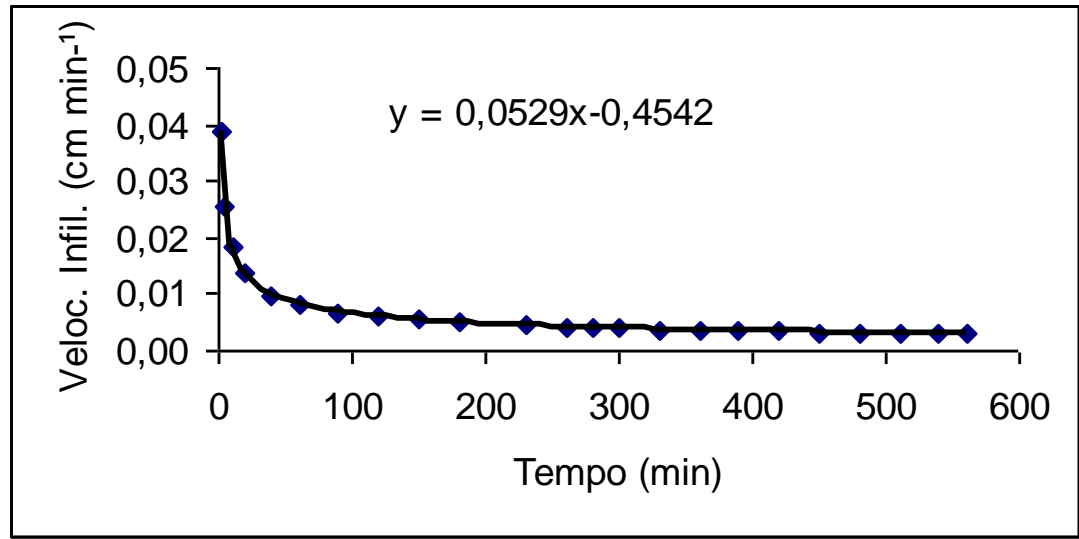

Figura 11- Gráfico da velocidade infiltração ao longo do ensaio no teste 1.

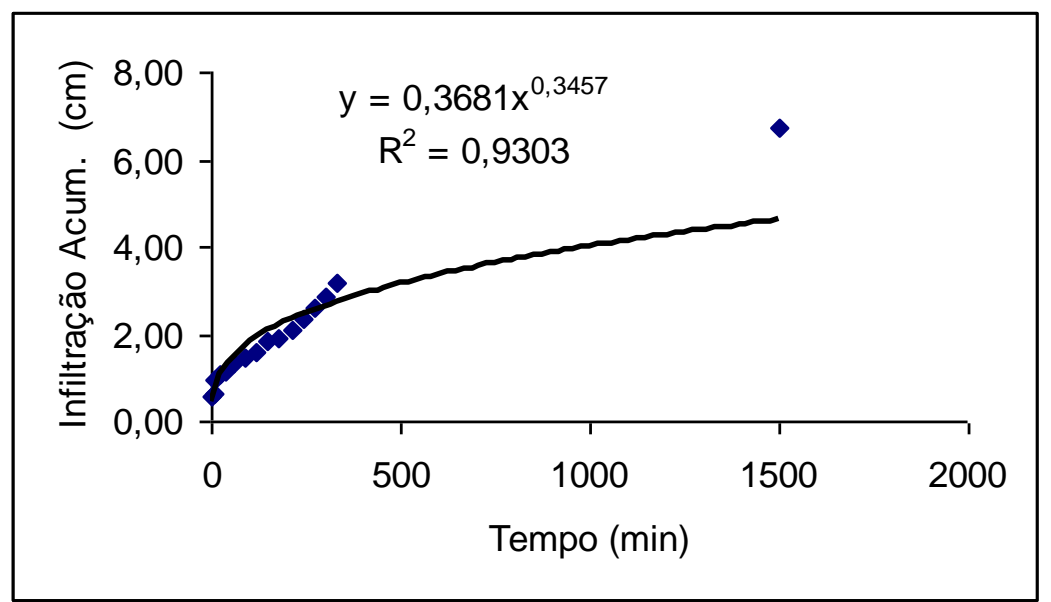

Figura 12- Gráfico de infiltração acumulada ao longo do período de ensaio no teste 2.

\footnotetext{
8 PEREIRA, A.C. E PORTO FILHO, F. (2007). ATERRO PARA RESÍDUOS INDUSTRIAIS: ESTUDO GEOTÉCNICO DE SOLOS PARA CAMADA DRENANTE E ANÁLISE DE ESTABILIDADE DE TALUDES. FUNDAÇÃO GUIMARÃES DUQUE - UFERSA,
} 39P. 


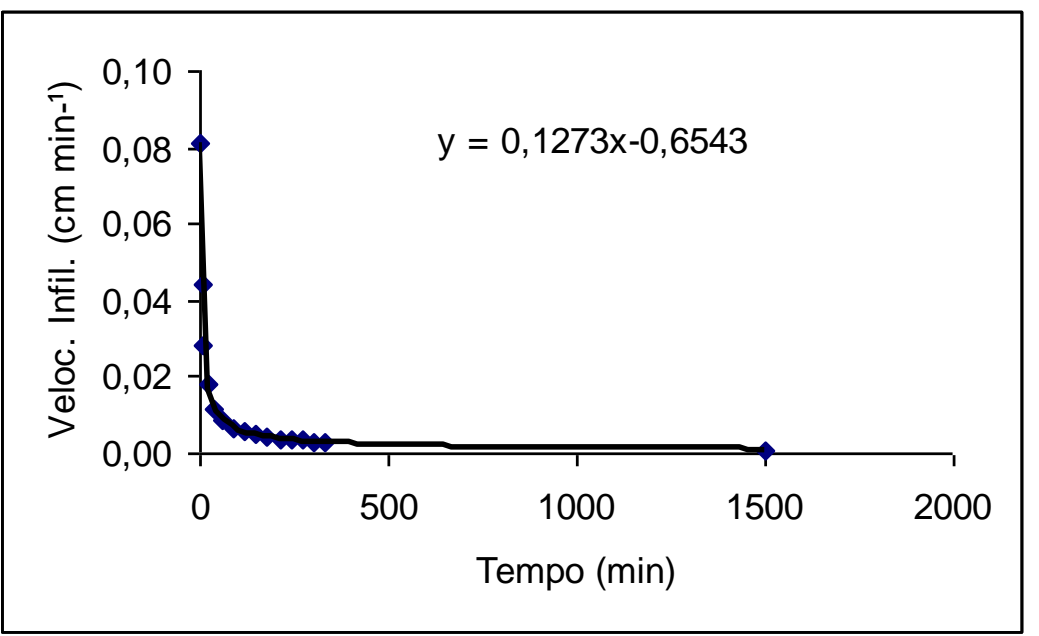

Figura 13- Gráfico da velocidade infiltração ao longo do ensaio no teste 2.

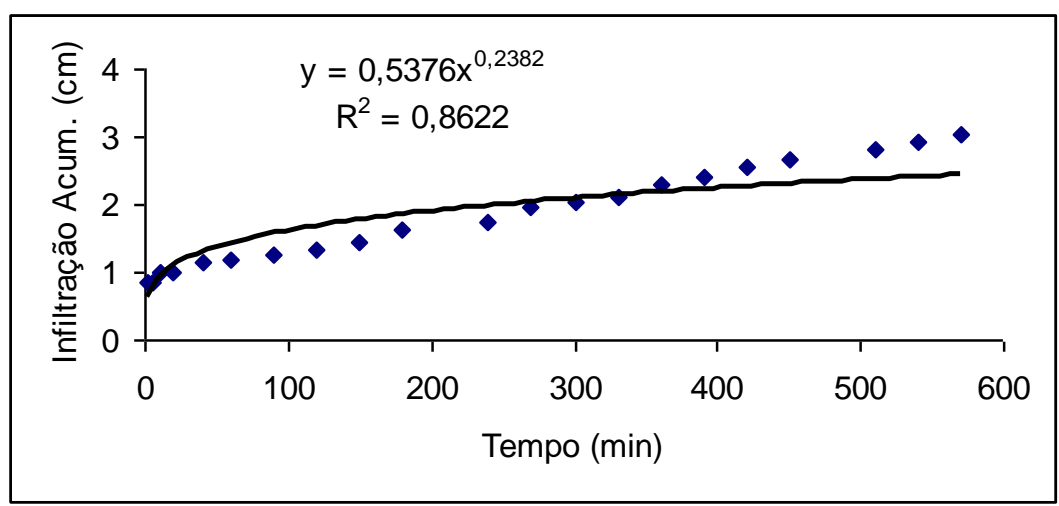

Figura 14- Gráfico de infiltração acumulada ao longo do período de ensaio no teste 3.

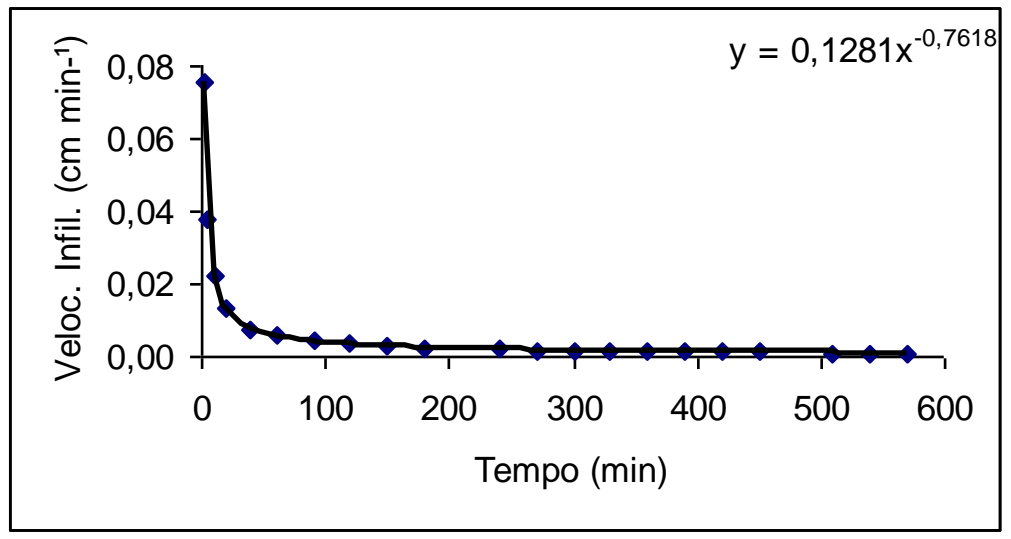

Figura 15- Gráfico da velocidade infiltração ao longo do ensaio no teste 3.

Assim, mediante o emprego da metodologia e equação apresentada por Millar (1978) ${ }^{9}$ para determinação da condutividade hidráulica da camada superficial, foram os seguintes os valores encontrados para o solo avaliado:

${ }^{9}$ Millar, A. A., Drenagem de Terras Agrícolas: Bases Agronômicas, MacGraw Hill, p. 126-127, São Paulo, 1978. 
Quadro 07- Condutividade hidráulica $K_{20}$ para o solo estudado (cm/s) (Pereira e Porto Filho, 2007).

\begin{tabular}{|c|c|c|c|}
\hline Ponto & $\begin{array}{c}\mathrm{lb} \\
\left(\mathrm{cm} \mathrm{s}^{-1}\right)\end{array}$ & $\begin{array}{c}\mathrm{K}=\mathrm{lb} \cdot \mathrm{P} / \mathrm{H}+\mathrm{P}+\mathrm{H}_{\mathrm{k}} \\
\left(\mathrm{cm} \mathrm{s}^{-1}\right)\end{array}$ & $\begin{array}{c}\mathrm{K}_{20} \\
\left(\mathrm{~cm} \mathrm{~s}^{-1}\right)\end{array}$ \\
\hline 1 & $4,98 \times 10^{-5}$ & $3,46 \times 10^{-5}$ & $2,76 \times 10^{-5}$ \\
\hline 2 & $1,77 \times 10^{-5}$ & $1,27 \times 10^{-5}$ & $1,01 \times 10^{-5}$ \\
\hline 3 & $1,70 \times 10^{-5}$ & $1,15 \times 10^{-5}$ & $9,19 \times 10^{-6}$ \\
\hline \multicolumn{3}{|r|}{ Média } & $1,56 \times 10^{-5}$ \\
\hline
\end{tabular}

Portanto, como valores médios para a condutividade hidráulica do solo ensaiado, corrigido para temperatura da água a $20^{\circ} \mathrm{C}$, teríamos $\mathrm{K}_{20}=1,56 \times 10^{-5} \mathrm{~cm} \mathrm{~s}^{-1}$ (célula 01 ) e, como pode-se observar, o solo ensaiado ("Solo 1 ") se apresentou com comportamento silto-argiloso frente à sua condutividade hidráulica, de forma coerente com a classificação do solo como $\mathrm{MH}$ (siltoso de alta compressibilidade).

\subsection{Análise da Estabilidade dos Taludes}

Considerando que a análise da estabilidade dos taludes consiste na assunção de adequado valor para o Fator de Segurança em relação à resistência ao cisalhamento do solo, entendido como sendo a relação entre esforços estabilizantes (resistentes) e esforços instabilizantes (atuantes), para determinado método de cálculo adotado ter-se-ia os Fatores de Segurança (FS) para cobrir as incertezas naturais das diversas etapas de dimensionamento.

Convém que se destaque que o enquadramento em cada caso previsto nos Tabelas 1 e 2 da Norma NBR 11682/04 deverá ser justificado pelo projetista, sempre de comum acordo com o proprietário da área afetada e atendendo às exigências dos órgãos públicos competentes.

Assim, o Fator de Segurança mínimo a ser adotado no projeto deverá ser obtido de acordo com o proposto pela Tabela 3 da citada Norma (Quadro 08).

Quadro 08- Fatores de segurança (NBR 11682/04 ${ }^{10}$ : Tabela 3).

\begin{tabular}{|c|c|c|c|}
\hline $\begin{array}{c}\text { Grau de segurança } \\
\text { Perdas de vidas }\end{array}$ & Alto & Média & Baixo \\
Perdas materiais e ambientais & $\mathbf{1 , 5}$ & 1,4 & 1,3 \\
\hline Alto & 1,4 & 1,3 & $1,2^{(*)}$ \\
\hline Médio & 1,4 & 1,3 & $1,10^{(*)}$ \\
\hline Baixo &
\end{tabular}

(") A adoção de fatores de segurança iguais ou inferiores a 1,2 só será permitida quando os parâmetros de resistência do solo puderem ser confirmados por retroanálise, para as condições mais desfavoráveis de poropressões. No caso de estabilidade de blocos rochosos os fatores de segurança podem ser parciais, incidindo sobre $\gamma, \phi$ e $C^{\prime}$, em função da incerteza sobre estes parâmetros, devendo ser justificado pelo projetista. Deve-se também adotar um fator de segurança mínimo sobre o método de cálculo empregado, igual a 1,1.

A partir da análise de estabilidade do aterro conforme procedimentos preconizados na NBR 11.682 (2004), inclusive com a redução dos parâmetros de resistência do solo em 40\%, verificou-se que para as condições analisadas, de modo geral, o aterro apresenta-se estável, não estando sujeito a deslizamentos de grandes proporções.

${ }^{10}$ NORMA ABNT NBR 11.682/04: ESTABILIDADE DE TALUDES - PROCEDIMENTOS. 
Quadro 09- Situações com e sem Percolação: Rompimento Global ${ }^{11}$.

\begin{tabular}{|c|c|c|c|}
\hline \multirow[t]{2}{*}{ SPR } & \multicolumn{3}{|c|}{ SEM PERCOLAÇÃO } \\
\hline & Fellenius & Bishop & Janbu \\
\hline SOLO 2 & 2,13 & 2,47 & 2,15 \\
\hline SOLO 2 & 3,23 & 3,72 & 3,25 \\
\hline SOLO 3 & 2,13 & 2,47 & 2,15 \\
\hline SOLO 3 & 3,23 & 3,72 & 3,25 \\
\hline \multirow[t]{2}{*}{ SPR } & \multicolumn{3}{|c|}{ COM PERCOLAÇÃO } \\
\hline & Fellenius & Bishop & Janbu \\
\hline SOLO 2 & 1,50 & 1,84 & 1,62 \\
\hline SOLO 2 & 2,12 & 2,62 & 2,31 \\
\hline SOLO 3 & 1,49 & 1,83 & 1,61 \\
\hline SOLO 3 & 2,11 & 2,61 & 2,30 \\
\hline
\end{tabular}

As análises da estabilidade por métodos de equilíbrio-limite, sem o auxilio da ferramenta computacional, mostraram que o talude apresenta-se estável nas condições que prevalecem tanto na estação seca como na época das chuvas, onde pode haver percolação de água, com fatores de segurança mínimo $(F S m i n=1,49)$ calculado pelo método de Fellenius com o emprego do solo 3 .

Nessa situação, quando considerado os valores obtidos pelo método de Bishop, mais preciso, verifica-se que a estabilidade está assegurada devido ao Fator de segurança mínimo ser maior do que o valor fixado na NBR 11.682 (2004), de (FS = 1,5). Nesse caso sugere-se o emprego do solo 2 como solução construtiva do aterro.

As análises da estabilidade por métodos de equilíbrio-limite, com o auxilio da ferramenta computacional, mostraram que o talude apresenta-se estável e não sujeito a grandes deslizamentos, pois os fatores de segurança calculados por diferentes métodos resultaram valores bem maiores que o mínimo $\left(\mathrm{FS}_{\min }=1,5\right)$ para qualquer um dos métodos utilizados, mesmo com a redução dos parâmetros de resistência dos solos em $40 \%$.

Quadro 10- Análise para situações sem percolação (ruptura no talude).

\begin{tabular}{|c|c|c|c|}
\hline \multirow{2}{*}{ SPR } & \multicolumn{3}{|c|}{ SEM PERCOLAÇÃO } \\
\cline { 2 - 4 } & Fellenius & Bishop & Janbu \\
\hline SOLO 2 C/ REDUÇÃO & 1,591 & 1,660 & 1,555 \\
\hline SOLO 2 S/ REDUÇÃO & 2,525 & 2,621 & 2,471 \\
\hline SOLO 3 C/ REDUÇÃO & 1,308 & 1,367 & 1,285 \\
\hline SOLO 3 S/ REDUÇÃO & 2,044 & 2,145 & 2,009 \\
\hline
\end{tabular}

\footnotetext{
${ }^{11}$ Os fatores de segurança são praticamente os mesmos, pois a superfície potencial de ruptura (SPR) foi imposta para ocorrer no resíduo.
} 
Quadro 11- Análise para situações sem percolação (ruptura global).

\begin{tabular}{|c|c|c|c|}
\hline \multirow{2}{*}{ SPR } & \multicolumn{3}{|c|}{ SEM PERCOLAÇÃO } \\
\cline { 2 - 4 } & Fellenius & Bishop & Janbu \\
\hline SOLO 2 C/ REDUÇÃO & 1,854 & 1,907 & 1,835 \\
\hline SOLO 2 S/ REDUÇÃO & 2,823 & 2,904 & 2,790 \\
\hline SOLO 3 C/ REDUÇÃO & 1,831 & 1,882 & 1,812 \\
\hline SOLO 3 S/ REDUÇÃO & 2,784 & 2,863 & 2,753 \\
\hline
\end{tabular}

\section{CONSIDERAÇÕES FINAIS}

Considera-se que a metodologia utilizada com o objetivo de caracterizar solos naturais e solos compactados para projeto e execução de células de aterro para resíduos industriais oriundos da atividade petrolífera, apresenta-se como suficientemente adequada visando avaliar a segurança da obra frente ao risco de contaminação pela percolação pela base dos aterros, bem como referente à avaliação da segurança frente ao risco de ruptura dos taludes de contenção.

As análises de resultados de sondagens geotécnicas realizadas conduziram à conclusão de que o solo investigado caracteriza-se pela rápida ocorrência de estratos com valores para o índice de resistência à penetração superior a 20 golpes $/ 30 \mathrm{~cm}$, sendo que em 10 dos perfis $(2 / 3$ do total) foram encontrados $\mathrm{N}_{\text {SPT }} \geq 20$ ainda no primeiro metro de ensaio.

Quanto às prospecções geofísicas realizadas, verifica-se a inexistência de estruturas importantes que condicionem a presença de aqüíferos suspensos, tanto devido a não identificação de nível d'água (lençol freático) em todos os 15 furos de sondagem realizados em setembro/2007, como pela a reduzida espessura de cobertura de solo e a natureza de carência na intercomunicação entre as fraturas identificadas nas formações superficiais (predominantemente calcários margosos) na área da prospecção geofísica.

Considera-se, portanto, em função dos resultados encontrados na prospecção geofísica, que a área estudada não apresenta formações e estruturas geológicas com potencialidade de propriedades hidrogeológicas características de áreas suscetíveis para acumulação de água, como indicam tanto os resultados da sondagem elétrica vertical como os perfis elétricos realizados. Os estudos de campo realizados para a determinação da condutividade hidráulica dos solos indicam que os materiais avaliados podem ser caracterizados como de baixa condutividade hidráulica. Em relação aos finos presentes nos solos, pode-se caracterizá-los como de plasticidade mediana a alta e de alta compressibilidade ( $L L>50 \%$ ).

As análises da estabilidade por métodos de equilíbrio-limite, com o auxilio da ferramenta computacional (programa Geoslope), mostraram que o talude apresenta-se estável e não sujeito a grandes deslizamentos, pois os fatores de segurança calculados por diferentes métodos resultaram valores bem maiores que o mínimo (FSmin $=1,5$ ) para qualquer um dos métodos utilizados, mesmo com a redução dos parâmetros de resistência dos solos em $40 \%$.

\section{REFERÊNCIAS BIBLIOGRÁFICAS}

1. Cavalcante, S.P.P e Coutinho, R.Q. Análise de Parâmetros Geotécnicos dos Solos Compactados de Barargens do Estado do Ceará, In: COBRAMEG'2006, pp. 2025-2030, 2006. 
2. Cruz, P.T. Propriedades de Engenharia de Solos Residuais Compactados da Região Sul do Brasil, THEMAG/DLP/EPUSP, São Paulo, 1969.

3. Cruz, P.T. 100 Barragens Brasileiras: Casos Históricos, Materiais de Construção e Projeto, Oficina de Textos/FAPESP, São Paulo, 1995.

4. Klar, E. A., Irrigação: Freqüência e Quantidade de Aplicação, Nobel, p. 66-79, São Paulo, 1991.

5. Millar, A. A., Drenagem de Terras Agrícolas: Bases Agronômicas, MacGraw Hill, p. 126-127, São Paulo, 1978.

6. Norma ABNT NBR 11.682/04: Estabilidade de Taludes - Procedimentos.

7. Norma ABNT NBR 6459/84: Determinação do Limite de Liquidez.

8. Norma ABNT NBR 7180/84: Determinação do Limite de Plasticidade.

9. Norma ABNT NBR10.004/2004: Resíduos sólidos - Classificação.

10. Norma ABNT NBR 7.182/84: Solo - Ensaio de Compactação - Procedimento.

11. Norma DNER-ME 162/94: Solos - ensaio de compactação utilizando amostras trabalhadas.

12. Pereira, A.C. e Porto Filho, F.Q. (2007). Aterro para Resíduos Industriais: Estudo Geotécnico de Solos para Camada Drenante e Análise de Estabilidade de Taludes. Fundação Guimarães Duque - UFERSA, 39p.

13. Pereira, A.C. e Porto Filho, F.Q. (2006). Aterro Sanitário: Caracterização Físico-Hídrica de Solos. Fundação Guimarães Duque - UFERSA, 21p. 